\title{
A FORMAÇÃO DOCENTE EM GÊNERO E RAÇA/ETNIA E A PERSPECTIVA DE TRANSFORMAÇÃO SOCIAL
}

\author{
Rosana Monti Henkin ${ }^{1}$ \\ Bartolina Ramalho Catanante ${ }^{2}$
}

\section{RESUMO}

Este trabalho tem por objetivo estabelecer uma conexão entre o papel da escola, enquanto aparelho ideológico do Estado e executora de políticas públicas educacionais, e as raízes das desigualdades construídas pela sociedade capitalista, racista e sexista,buscando compreender possíveis caminhos para a sua superação.O objeto de estudo é o projeto Gênero e Diversidade na Escola (GDE),oferecido por parceria entre as secretarias de políticas para as Mulheres (SPM) e de Promoção da Igualdade Racial (SEPPIR) e a Secretaria de Educação Continuada, Alfabetização, Diversidade e Inclusão(SECADI/MEC), que visa a contribuir na formação continuada de profissionais de educação da rede pública de ensino, tratando articuladamente as relações de gênero, as relações étnico-raciais e a diversidade de orientação sexual,com vistas à transformação de mentalidades e práticas no interior da escola. Tomamos como base teórica a perspectiva marxista como fundamento da pesquisa educacional, buscando ver no confronto entre o movimento da nossa sociedade e a teoria nela produzida dados que demonstrem a origem das desigualdades. Nesse sentido, utilizaremos uma concepção de pesquisa que considere as dimensões tanto do singular quanto do universal.

Palavras-chave: Gênero; Raça/etnia; Formação de professores e professoras.

\section{TEACHER TRAINING IN GENDER AND RACE / ETHNICITY AND THE SOCIAL TRANSFORMATION PERSPECTIVE}

\begin{abstract}
This work aims to establish a connection between the role of the school, while ideological apparatus of the State and executing educational public policy, and the roots of inequality built by capitalist society, racist and sexist, seeking to understand potential paths to their resilience. The object of study is the project gender and diversity at school (GDE), offered by partnership between the secretariats of policies for women (SPM) and for the promotion of Racial Equality (Seppir) and the Secretariat of continuing education, literacy, diversity and inclusion (Secadi/MEC), which aims to contribute to the continuing education of professionals of education public schools, treating articulately gender relations, ethnic-racial relations and diversity of sexual orientation,with a view to transforming mentalities and practices within the school. We take as theoretical basis the Marxist perspective in support of educational research, seeking to view the confrontation between the movement of our society and the theory it produced data that demonstrate the origin of inequality. In this sense, we will use a research design that consider the dimensions both singular and universal.
\end{abstract}

Keywords: gender; Race/ethnicity; Training of teachers and professors. 


\section{INTRODUÇÃO}

Durante todo o século XX e até esta segunda década do XXI têm sido constantes as lutas pela igualdade de gênero, raça e etnia. O movimento de mulheres e o movimento negro, principalmente após a Constituição de 1988, têm orientado e contribuído na elaboração de políticas públicas que visam à garantia de direitos e ao combate à discriminação. Especialmente, desde 2003, existe um grande incentivo do governo federal para a elaboração, implantação de políticas púbicas e serviços quealmejam a igualdade social. A construção dos planos nacionais de Políticas para as Mulheres (PNPMs), dos planos nacionais de Promoção da Igualdade Racial, bem como os organismos governamentais necessários à sua operacionalização, e a realização de conferências em todos os níveis são exemplos dessa contribuição. Entretanto, a predominância de atitudes e convenções sociais discriminatórias ainda é uma realidade persistente e naturalizada.

Em que pese o Brasil ter conquistado importantes resultados na ampliação do acesso e no exercício dos direitos por parte de seus cidadãos e cidadãs, as discriminações de gênero e raça continuam sendo produzidas e reproduzidas em todos os espaços da vida social brasileira. A escola é um deles. Atividades separadas para meninos, meninas, valoração diferenciada por sexo, livros didáticos com conceitos distorcidos e vocabulário rotineiro discriminatório são exemplos da reprodução dessas discriminações.

Pretendemos neste estudo destacar os elementos que caracterizam uma análise na perspectiva marxista. Nosso objeto de estudo é o projeto Gênero e Diversidade na Escola (GDE) - organizado mediante parceria entre Presidência da República (RP), por intermédio das secretarias de Políticas para as Mulheres (SPM) e de Promoção da Igualdade Racial (SEPPIR), Ministério da Educação (MEC), por meio da Secretaria de Educação Continuada, Alfabetização, Diversidade e Inclusão (SECADI) e da extinta Secretaria de Educação a Distância (SEED), British Council, além do Centro LatinoAmericano em Sexualidade e Direitos Humanos do Instituto de Medicina Social da Universidade do Estado do Rio de Janeiro (CLAM/IMS/UERJ) -quem tem por finalidade contribuir na formação continuada de profissionais de educação da rede pública de ensino,tratando articuladamente as relações de gênero, as relações étnicoraciais e a diversidade de orientação sexual,visando à transformação de mentalidades e práticas.O curso GDE foi oferecido inicialmente em sua versão-piloto no ano de $2006 \mathrm{em}$ seis municípios brasileiros (Porto Velho, Salvador, Maringá, Dourados, Niterói e Nova Iguaçu) com um total de 1.200 vagas, priorizando professores e professoras das disciplinas de ensino fundamental, de $5^{\mathrm{a}}$ a $8^{\mathrm{a}}$ séries. Em Dourados dos 218 matriculados, 142 concluíram o curso. Desde 2008, o curso passou a ser oferecido para todas as instituições públicas de ensino superior dopaís que queiram ofertar o curso pelo sistema da Universidade Aberta do Brasil(UAB).

Na edição de 2008, foi assinado convênio com vinte universidades para oferta do GDE. Na primeira rodada, foram capacitados mais de 13 mil professoras e professores. O edital de 2009 para a implementação do curso recebeu adesão de mais dedez universidades, o que elevou para trinta instituições de ensino superior (IES) ofertantes, distribuídas por diversos estados brasileiros. Na edição 2010/2011, mais nove universidades federais e estaduais aderiram ao GDE. 
O curso GDE, até 2012, fazia parte da Rede de Educação para a Diversidade. A partir de 2013 está situado na Política Nacional de Formação de Profissionais do Magistério da Educação Básica- PARFOR, ação 20RJ do PPA.

Em Mato Grosso do Sul, a Universidade Federal de Mato Grosso do Sul (UFMS), por meio da Coordenadoria de Educação Aberta e a Distância, oferece desde 2009o referido curso. Nesse ano o curso foi oferecido nos pólos de Água Clara, Rio Brilhante e São Gabriel do Oeste, tendo 240 matrículas e 123 aprovações. Em 2013 o curso foi oferecido para os pólos de Camapuã, Campo Grande e Miranda, com 201 matrículas.

Dos 51 professores (as) de Campo Grande que concluíram o curso, 47 são mulheres e 4 são homens e 18 pessoas não informaram endereço, local de trabalho e telefone. Dos 33 que forneceram dados, 11 trabalhavam em Centros de Educação Infantil - CEINFs da rede púbica, 6 trabalhavam em escolas da rede municipal de Campo Grande, 5 pertenciam a instituições não governamentais, 11 trabalhavam em instituições que não oferecem educação básica.

Despertou nossa atenção a grande participação de professores e professoras da educação infantil e a pouca participação de profissionais do ensino fundamental. O que nos levou a conversar sobre esse dado com algumas pessoas envolvidas no projeto e observamos pelo discurso que muitas pessoas acreditam que é mais fácil implantar as temáticas de gênero e raçaletnia na educação infantil e séries iniciais devido à organização curricular das mesmas. Essas pessoas entendem que tais temas entrarão na escola por meio de projetos e que a educação infantil e as séries iniciais são mais adequadas para essa tarefa. Preocupa-nos a falta de percepção de que a transversalidade deve ocorrer na rotina da escola.

Se acreditamos que o movimento histórico se dá pela correlação de forças produtivas e que essa correlação se modifica na medida em que as relações de produção se transformam, então os grupos que compõem a sociedade também se transformam, as pessoas,em cada momento histórico, se organizam em grupos com características específicas.

Assim, cada nova geração apresenta necessidades próprias de seu momento histórico. A geração do século XXI tem necessidades diferentes da geração do século $\mathrm{XX}$, por isso falar de práticas inovadoras em educação significa falar de uma escola reflexiva que estabeleça a ponte entre a história coletiva do ser humano e a história do educando, visando aprender a trabalhar, aprender a conviver, aprender a pensar e pensarse, situar-se, selecionar conhecimentos, interligar, dar sentido às coisas; uma escola da diversidade, da diferença, da comunicação, da inclusão pela cultura; uma escola que tem a função de libertar pela aprendizagem e incluir pela cultura.

Para que a escola possa caminhar nessa direção é necessário que professores e professoras compreendam que o processo educacional também é formado por dimensões como a ética, as diferentes identidades, a diversidade, a sexualidade, a cultura, as relações raciais, entre outras. E trabalhar com essas dimensões significa ir além dos conteúdos escolares ou temas transversais. Significa ter a sensibilidade para perceber como esses processos constituintes da formação humana se manifestam na vida das pessoas e no próprio cotidiano escolar (MUNANGA,2005, p.143-154). 


\section{APORTE TEÓRICO}

Tomando como base a perspectiva marxista enquanto fundamento teórico da pesquisa educacional, buscamos, no confronto entre o movimento da nossa sociedade (capitalista, patriarcal, racista) e a teoria nela produzida os dados que informam nosso objeto (formação de professores e professoras em gênero eraça). Para tal, consideramos que a primeira etapa de qualquer investigação científica demanda uma análise capaz de captar as raízes do objeto e propor soluções precisas.

Nesse sentido, utilizamos uma concepção de pesquisa que considera as dimensões singular e universal. Uma simples indagação empírica apenas nos forneceria dados superficiais, como índices de violência contra as mulheres ou evasão escolar de estudantes negros. Entretanto, o que dá concretude ao objeto observado é o seu caráter histórico, ou seja, o fato de essa situação singular conter em si elementos universais, observáveis por meio de teorias que busquem a compreensão da historicidade do objeto, apreendendo o movimento do conjunto de seres humanos na produção da vida, suas contradições, seus embates ao longo dos tempos. Essas teorias mostram o movimento da humanidade até se criar a situação atual. Assim poderemos compreender a raiz e o movimento das pessoas na construção das desigualdades de gênero eraça desde o início da propriedade privada, aprofundando-se com o advento do sistema capitalista. Dessa forma, o objeto pode ser visto pelo olhar do empirismo e da concretude histórica.

O conceito de ciência que utilizamos é aquele cuja análise se encontra na sua capacidade de apreender, no âmbito das relações sociais, o próprio movimento da história que determinou e assim configurou esse objeto. O método historicista é capaz de levar

o leitor ao local, ao momento e às expressões exatas da discussão, mas $\mathrm{o}$ enfoque, o destaque, o comentário, a interpretação conferem à pesquisa a marca da subjetividade criativa, da preocupação política, da sensibilidade e do estilo pessoais (NOSELLA, 2004, p. 33).

Uma categoria capaz de validar os resultados de uma pesquisa é a história, poisbusca no interior de cada forma social as diferentes maneiras de produção da vida pela humanidade e mostra a passagem de uma forma para outra por meio do confronto entre forças sociais antagônicas e contraditórias.

Os elementos materiais de uma subversão total são, de um lado, as forças produtivas existentes e, de outro, a formação de uma massa revolucionária que se resolve, não só contra as condições particulares da sociedade existente até então, mas também contra a própria "produção da vida" vigente, contra a "atividade total" sobre a qual se baseia. [...]. Toda concepção histórica, até o momento, ou tem omitido completamente esta base real da história, ou a tem considerado como algo secundário, sem qualquer conexão com o curso da história (MARX; ENGELS, 1991, p. 57)

Segundo Gramsci (1991), quando as relações de produção começam a se modificar, o conhecimento hegemônico começa a ser questionado, pois não mais 
responde às necessidades daquela sociedade. A ciência é instrumento de resposta a essas necessidades(GRAMSCI, 1991). Nesse sentido Nosella (2008) chama a atenção para "a necessidade de se restabelecer a ligação dialética entre virtude e ciência, entre ética e pesquisa, entre autoridade política e consciência individual". O pesquisador deve saber para qual finalidade faz a pesquisa, pois o saber por si não resulta em contribuição para a consciência humana (NOSELLA, 2008).

$\mathrm{Na}$ perspectiva da história, as questões que se colocam como objeto de investigação representam uma maneira de responder às necessidades sociais de cada época. Cabe então investigar as necessidades impostas pela ordem social, capitalista, patriarcal e racistana perspectiva da luta e da apreensão das contradições.

Para Gramsci (1991),toda sociedade tem suas necessidades, que são produzidas pelos seres humanos por meio do trabalho. Os seres humanos trabalham para atender às necessidades sociais. A pesquisa também. Portanto, o problema de pesquisa deve responder a uma necessidade social, algo que merece resposta e que ainda não foi respondido. A construção desigual dos gêneros, a desigualdade de oportunidades e direitos para brancos e não-brancos são construções históricas produzidas pelos seres humanosno interior dessa sociedade. Da mesma forma, as respostas às necessidades oriundas dessa construção devem sair dessa sociedade (GRAMSCI, 1991).

Para compreender essa questão nos remetemos à compreensão do capitalismo e sua relação com o aprofundamento das desigualdades de gênero eraça.

O capitalismo é um modo de produção cujos princípios são o direito de propriedade individual aplicado ao capital e o direito à liberdade individual. A aplicação desses fundamentos divide a sociedade em duas classes básicas:proprietária ou possuidora do capital e a que vende a sua força de trabalho por não dispor do capital. As sociedades não são organizadas apenas pela categoria de classe, mas também pela articulação entre as estruturas de gênero e raça que combinam exploração e dominação. Patriarcado, racismo e capitalismo são faces distintas do mesmo modo de produzir e reproduzir a vida.

O patriarcado é um sistema sociopolítico e ideológico que divide os gêneros, colocando-os em uma relação hierárquica baseada no controle da sexualidade feminina. O masculino, nessa perspectiva, é, na maior parte do tempo, mais valorizado do que o feminino, este geralmente percebido como o outro imperfeito daquele(SAFFIOTI, 2004, p.49).

As sociedades que se organizaram a partir da ideologia do patriarcado e da divisão da terra para a agricultura desenvolveram um padrão de organização que estimulava a necessidade de ampliar a propriedade, fazendo com que alguns grupos dominassem outros grupos, formando as primeiras aldeias, depois as cidades, as cidadesestado, os primeiros Estados e os impérios.Quando um povo conquistava outro, os homens eram eliminados ou transformados em escravos, e as mulheres eram preservadas, pois serviam aos propósitos de constituir força de trabalho, reproduzir força de trabalho e prestar serviços sexuais aos homens do povo vitorioso.

Note-se que o gênero não é tão somente social, pois dele participa também o corpo, quer como força de trabalho, quer como objeto sexual, quer, ainda, como reprodutor de seres humanos, cujo destino, se fossem homens, seria participar ativamente 
da produção e, quando mulheres, seria entrar com as três funções na engrenagem descrita. As desigualdades de gênero produzidas pelo patriarcado se aprofundam com o capitalismo, uma vez que as mulheres passam a desempenhar as tarefas de produção e reprodução com vista ao mercado, produzindo a força de trabalho que servirá ao sistema.

$\mathrm{O}$ racismo tem como base o escravismo. Nasceu no mesmo momento histórico em que surgiu o sexismo: o da expansão da propriedade privada, demonstrando que existe uma estrutura de poder que unifica as ordens de gênero, raça e classe social(SAFFIOTI, 2004, p.67).

"Ao longo de toda a história da humanidade, os povos mais diversos mantiveram contatos e trocas, aproveitando-se das coisas boas que encontravam uns nos outros" (GÊNERO..., 2009, p.192). Como "[...] os povos têm tendência a afirmar que o seu modo de vida é melhor" (GÊNERO..., 2009, p.191), os povos antigos tinham todo o cuidado para diminuir o risco de mal-entendidos que prejudicassem as trocas. Na medida em que os povos começam a migrar e se misturar, as diferenças entre culturas passaram a servir para controlar as relações dentro "[...] de uma mesma sociedade. Uma dessas formas, talvez a mais perversa dentre elas, é o racismo" (GÊNERO..., 2009, p.192).

O racismo é uma doutrina, ou seja, um tipo de conhecimento que se mantém por repetição, ignorância e preconceito, mas que guarda pretensões de se apresentar como conhecimento objetivo, supostamente sustentado na natureza das coisas. Tem em sua origem dois fatos históricos de enorme importância: a afirmação da ciência positiva contra as teorias religiosas na explicação da origem e das diferenças entre as pessoas; e a expansão colonial européia que, por meios militares, religiosos e comerciais, dominou grandes extensões de terras ultramar, onde habitavam povos com culturas e aparências físicas muito diferentes daquelas dos europeus.

$\mathrm{Se}$

O racismo é uma doutrina que afirma não só a existência das raças, mas também a superioridade natural e, portanto, hereditária, de umas sobre as outras, a atitude racista, por sua vez, é aquela que atribui qualidades aos indivíduos ou aos grupos conforme o seu suposto pertencimento biológico a uma dessas diferentes raças e, portanto, de acordo com as suas supostas qualidades ou defeitos inatos e hereditários (GÊNERO..., 2009, p.196).

É uma forma de usar as diferenças como um modo de dominação e subordinação. O termo raça só se afirmou como forma de explicar diferenças entre espécies a partir do século XIX, em decorrência do desenvolvimento de teorias biológicas e evolucionistas. Seu aspecto positivo foi o de explicar cientificamente a anatomia e evolução de homens e mulheres. Por outro lado, quando essas teorias começaram a ser utilizadas "[...] para tentar explicar as diferenças biológicas, anatômicas ou de simples aparência física,[...] para associá-las a outras diferenças, basicamente de caráter moral" (GÊNERO..., 2009, p.193), difundiu-se a ideia de que humanidade estaria dividida em tipos raciais, os quais “[...] não tinham as mesmas capacidades para 'evoluir' culturalmente ou 'progredir' socialmente" (GÊNERO..., 2009, p.194). 
Existe no Brasil a tendência de uma parcela significativa dos setores dominantes negar a raça como aspecto gerador de desigualdades sociais. A colonização é um dos fatores históricos responsáveis por essa omissão.

A persistência das profundas desigualdades sociais, entre os brasileiros, estaria associada ao desenvolvimento e reprodução de um caldo de cultura peculiar aos povos ibéricos, denominado [...] de individualismo anárquico. A característica principal desse individualismo anárquico seria um culto à pessoa em detrimento do grupo ou conjunto, impedindo formas de coesão social e de apreciação coletiva, em especial, de leis e normas jurídicas que pudessem orientar o conjunto da sociedade (COMPARATO, 1998, p.49, apud SILVÉRIO, 2002, p.221).

O modelo brasileiro de classificação racial é o da multipolaridade, o que permite que os indivíduos possam ser classificados de diversas maneiras, favorecendo uma "desracialização" da identidade individual. Um exemplo disso é o costume de chamar de morenos os afrodescendentes. A nomenclatura "moreno/a" serviria tanto a descendentes de africanos como a descendentes de europeus, já que significa pele branca e cabelo preto. $\mathrm{Na}$ verdade, os afrodescendentes são pessoas negras e não morenas, e quando são sinalizados como negros, isso é feito de forma pejorativa. Essa ambiguidade não impede "[...] que uma parcela significativa da população negra seja permanentemente racializada no cotidiano e que, por isso mesmo, tenha assumido sua identidade negra de forma nãoambígua e contrastante em relação ao seu outro, o branco" (SILVÉRIO, 2002, p.224).

No Brasil, em linhas gerais, para setores específicos da sociedade,o debate sobre as más condições de vida de grande parte da população desconsidera o componente étnico. De acordo com Silvério, em suas considerações críticas interpretando e analisando Comparato (1998, p.54)sobre essa postura,

a desigualdade entre ricos e pobres seria a principal fonte de preconceitos e atritos e o grande fator de atraso da sociedade brasileira. E é inconsciente. A desigualdade entre brancos e negros, decorrente da escravidão, seria a principal fonte de geração e manutenção de hierarquias sociais vinculadas ao pertencimento racial (SILVÉRIO, 2002, p.222).

Embora aponte a desigualdade entre negros e brancos como "[...] muito forte", Comparato a considera"[...] abaixo da desigualdade entre ricos e pobres" (1998, p.54). Ao contrário, Silvério faz uma análise mais abrangente e multidimensional sobre os desequilíbrios socioeconômicos no Brasil.

Creio que as desigualdades são um produto de uma trama complexa entre o plano econômico, político e cultural. Além disso, a multiplicidade de fatores na explicação das desigualdades tem a vantagem de mostrar tanto a multicausalidade dos elementos explicativos da vida social quanto o aspecto dinâmico e relacional das relações sociais (2002, p.222).

Essa macro leitura da realidade brasileira tem em Gramsci (1991)um importante fundamento para reflexão. O filósofo marxista italiano afirma que todo movimento cultural que pretenda substituir o senso comum e as velhas concepções do mundo necessita: não se cansar jamais de repetir os próprios argumentos e trabalhar 
incessantemente para elevar intelectualmente as camadas populares, criando elites intelectuais de um novo tipo, que surjam da massa e que permaneçam em contato com ela para tornarem-se seus sustentáculos e assim modificando o panorama ideológico de uma época.

Para Marx e Engels, "o que os indivíduos [...] são depende das condições materiais de sua produção" (1991, p.28). O sujeito se constitui nas condições de produção e reprodução social, pois uma formação social que não reproduz as condições de produção,ao mesmo tempo em que produz, não sobrevive por muito tempo. Cada época tem o aparato ideológico que sustenta a sua existência reproduzindo as respectivas relações de produção.

Nesse sentido o conceito de ideologia de Gramsci revela um conhecimento próprio da práxis interativa, na medida em que mobiliza conhecimentos, normas e valores relativos aos objetos visados. Ideologia é uma concepção de mundo que se manifesta na ação e a organiza, "é unidade de fé entre uma concepção de mundo e uma norma de conduta adequada a essa concepção".Assim, o conhecimento é ideológico porque reflete as aspirações e os projetos do sujeito que atua na realidade social (COUTINHO, 2003, p.103-114).Nessa lógica, a escola, enquanto aparelho ideológico de Estado reproduz as regras que garantem o funcionamento do sistema (ALTHUSSER, 2001, p.68).O sistema escolar reproduz o sexismo e o racismo, além da desigualdade de classes, seja por meio de conteúdos que interessam para a manutenção do sistema, seja por atitudes discriminatórias, seja por valores distorcidos.

Entretanto,os indícios de que a sociedade capitalista, racista e sexista está em seu limiar são perceptíveis, porque suas relações entraram em colapso,o que possibilita o surgimento de outra sociedade.

Dessa forma, enquanto política pública, a escola pode apaziguar o caos social, construindo, reproduzindo novos valores e relações com base na tolerância, na valorização das diferenças e incentivando o pensamento crítico, o que, segundo Marx, seria transformador.

\section{CONSIDERAÇÕES FINAIS}

O objetivo deste trabalho foi estabelecer uma conexão entre o papel da escola, enquanto aparelho ideológico de Estado e executora de políticas públicas educacionais, e as raízes das desigualdades construídas pela sociedade capitalista, racista e sexista, buscando compreender possíveis caminhos para a sua superação.

Apresentamos o aporte teórico que acreditamos esclarecer com maior profundidade as questões de pesquisa. Analisar a construção das desigualdades a partir da perspectiva histórica nos dá segurança de realizar um estudo com bases concretas, pois a história da humanidade é a história das relações sociais, das pessoas realizando suas ações concretamente, no contexto da produção e reprodução das relações. É a história da luta de classes, é a história da resistência das mulheres, é a história da resistência dos povos dominados e escravizados.

Refletimos a respeito da importância da formação de professores nas temáticas de gênero e raça como forma de construir novos valores que produzam relações igualitárias, 
em que a tolerância e o respeito à diversidade sejam ponto pacífico. Num momento de transição, no qual as forças estão em desequilíbrio, com as relações estabelecidas ruindo, é possível interferir de forma planejada na reorganização dessas relações de forma que todas as pessoas tenham garantido os seus direitos, o seu espaço, a sua humanidade. Entendemos que a escola pode ser o local inicial dessa transformação.

Considerando as raízes históricas, é possível escrever uma nova história, de forma coletiva, valorizando o protagonismo de todas as pessoas e grupos que formam essa sociedade.

\section{REFERÊNCIAS}

ALTHUSSER, Louis. Aparelhos Ideológicos de Estado: nota sobre os aparelhos ideológicos do estado (AIE). Traduzido por Walter José Evangelista e Maria Laura Viveiros de Castro.8.ed. Rio de Janeiro: Graal, 2001.

COMPARATO, Fábio Konder. O princípio da igualdade e a escola. Cadernos de Pesquisa, São Paulo, n.104, p.47-57, jul. 1998.Disponível em: <http://educa.fcc.org.br/pdf/cp/n104/n104a04.pdf> acesso em: 16 ago. 2013.

COUTINHO, Nelson. Gramsci: um estudo sobre seu pensamento político. Riode Janeiro: Civilização Brasileira, 2003.

GÊNERO e diversidade na escola: formação de professoras/es em gênero, sexualidade, orientação sexual e relações étnico-raciais. Livro de conteúdo: versão 2009. Rio de Janeiro: Cepesc; Brasília: SPM, 2009. Disponível em: <http://estatico.cnpq.br/portal/premios/2013/ig/pdf/genero_diversidade_escola_2009.pdf $>$ Acesso em 13 ago. 2013.

GRAMSCI, A. Concepção dialética da história. 9.ed. Rio de Janeiro: Civilização Brasileira, 1991.

MARX, K. ; ENGELS, F.A ideologia alemã (I - Feuerbach). Traduzido por José Carlos Bruni e Marco Aurélio Nogueira.8.ed. São Paulo: Hucitec, 1991.

MUNANGA, Kabengele, organizador.Superando o Racismo na Escola. $2^{\mathrm{a}}$ edição revisada, [Brasília]: Ministério da Educação, Secretariade Educação Continuada, Alfabetização e Diversidade, 2005.

NOSELLA, Paolo. “A Escola de Gramsci. 3. ed. - São Paulo: Cortez, 2004.

"Educação e. Sociedade, Campinas, vol. 29, n. 102, p. 255-273, jan./abr.

2008Disponível em <http://www.cedes.unicamp.br>

SAFFIOTI, Heleieth Iara Bongiovani. Gênero, patriarcado, violência. São Paulo: Fundação Perseu Abramo, 2004. (Coleção Brasil Urgente). 
SILVÉRIO, Valter Roberto. Ação afirmativa e o combate ao racismo institucional no Brasil. Cadernos de pesquisa, São Paulo, n.117, p.219-246, nov. 2002. Disponível em: <http://www.scielo.br/pdf/cp/n117/15560.pdf> Acesso em: 15 ago. 2013.

SOUZA, Ana Aparecida Arguelho; et al. "Sobre(o)viver de crianças e adolescentes: umareflexão acerca do método de pesquisa. InterMeio, Campo Grande, v. 9, n.18, p.104117,2003.Disponível em:http://www.intermeio.ufms.br/ojs/index.php/intermeio/article/view/187/181>Acesso em: 20ago. 2013

\footnotetext{
${ }^{1}$ Professora de história, pós-graduanda do Curso de Mestrado Profissional em Educação da Universidade Estadual de Mato Grosso do Sul (UEMS), e-mail: rosana.henkin@ @otmail.com

${ }^{2}$ Doutora em Educação pela Universidade Federal de São Carlos (UFSCar), docente do Curso de Mestrado Profissional em Educação da UEMS, e-mail: bartolina@uems.br

Recebido: março-14 Aprovado: dezembro-14
} 